\title{
PRODUÇÃO CIENTÍFICA SOBRE LETRAMENTO: MAPEAMENTO BIBLIOMÉTRICO DAS TESES DA BDTD (1997-2016)
}

\author{
Raquel Juliana Prado Leite de Sousa' \\ 'Universidade Federal de São Carlos (UFSCar), São Carlos (SP), Brasil; quel.leite@gmail.com
}

\begin{abstract}
Resumo
A fim de identificar a constituição do campo científico do letramento no Brasil, foram analisadas 237 teses defendidas entre 1997 e 2016 disponiveis na Biblioteca Digital Brasileira de Teses e Dissertações, o que permitiu a realização de um mapeamento bibliométrico enfocando as variáveis: a) evolução temporal; b) distribuição geográfica e institucional; e c) orientação e gênero. Observou-se crescimento de pesquisas de doutorado sobre o tema, com 88,6\% tendo sido defendidas entre 2007 e 2016. Percebeu-se uma discrepância geográfica, com 51,48\% de teses desenvolvidas no Sudeste e nenhum trabalho realizado no Norte. A frente de orientadores apontou para um grupo de 10 docentes com mais orientações. Verificou-se que $74 \%$ das orientações, $82,28 \%$ da autoria e $100 \%$ da frente de orientadores são formados por pesquisadores do gênero feminino. Os indicadores lançam luz à compreensão do campo científico sobre letramento no Brasil pela identificação de algumas de suas raízes históricas.
\end{abstract}

LETRAMENTO • PESQUISA • BIBLIOTECONOMIA • INDICADORES

\section{CONSTITUTION OF THE SCIENTIFIC FIELD OF LITERACY: BIBLIOMETRIC MAPPING OF THE BDTD THESES (1997-2016)}

\section{Abstract}

In order to identify the constitution of the scientific field of literacy in Brazil, 237 theses defended between 1997and 2016 available at the Biblioteca Digital Brasileira de Teses e Dissertações [Brazilian Digital Library of Theses and Dissertations] were analyzed, which allowed the realization of a bibliometric mapping focusing on the variables: a) temporal evolution; b) geographical and institutional distribution; and c) orientation and gender. There was an increase in doctoral research on the topic, 88.6\% of which were defended between 2007 and 2016. A geographic discrepancy can be seen, with $51.48 \%$ of theses developed in the Southeast and no work carried out in the North. The research front shows a group of 10 teachers with more guidance. It was found that $74 \%$ of the guidelines, $82.28 \%$ of the authorship and 100\% of the supervisors' front are formed by female researchers. The indicators shed light on the understanding of the scientific field on literacy in Brazil by identifying some of its historical roots.
\end{abstract}




\section{PRODUCTION SCIENTIFIQUE SUR LA LITTÉRATIE: CARTOGRAPHIE BIBLIOMÉTRIQUE DES THĖSES DE LA BDTD (1997-2016)}

\section{Résumé}

Afin d'identifier la constitution du champ scientifique de la littératie au Brésil, cette étude a analysé 237 thèses, soutenues entre 1997 et 2016, disponibles dans la Biblioteca Digital Brasileira de Teses e Dissertações [Bibliothèque Numérique Brésilienne de Thèses]. Ce travail a permis de réaliser une cartographie bibliométrique axée sur les variables suivantes: a) l'évolution temporelle; b) la distribution géographique et institutionnelle; et c) la direction de thèse et genre. Une augmentation de la recherche doctorale sur le sujet a pu être observée, avec la realisation de 88,6\% des soutenances entre 2007 et 2016. Une disparité géographique a aussi été constatée, 51,48\% des thèses dans le Sud-Est et aucune dans le Nord du pays. La variable directeurs de thèse a mis en évidence l'existence d'un groupe de 10 professeurs retenant un plus grand nombre de directions: $74 \%$ des directeurs, $82,28 \%$ des auteurs et $100 \%$ du peloton de tête des directeurs de thèse étaient des chercheurs du sexe féminin. Ces indicateurs identifient certaines des racines historiques du champ scientifique de la littératie au Brésil et apportent de la lumière à sa comprehension.

\section{LITTÉRATIE • RECHERCHE • BIBLIOTHÉCONOMIE • INDICATEURS}

\section{PRODUCCIÓN CIENTÍFICA SOBRE LETRAMIENTO: MAPEO BIBLIOMÉTRICO DE LAS TESIS DE LA BDTD (1997-2016)}

\section{Resumen}

Con el propósito de identificar la constitución del campo científico del letramiento en Brasil, se analizaron 237 tesis defendidas entre 1997 y 2016 disponibles en la Biblioteca Digital Brasileira de Teses e Dissertações, lo que permitió que se realizara un mapeo bibliométrico con enfoque en las siguientes variables: a) evolución temporal; b) distribución geográfica e institucional; $y$ c) orientación y género. Se observó un crecimiento de investigaciones de doctorado sobre el tema, con un 88,6\% defendido entre 2007 y 2016. Se percibió una discrepancia geográfica, con 51,48\% de tesis desarrolladas en el Sureste y ningún trabajo realizado en el Norte del país. El equipo de tutores señaló un grupo de 10 docentes con más orientaciones. Se verificó que el 74\% de las orientaciones, un 82,28\% de la autoría y un 100\% del equipo de tutores son formados por investigadores del género femenino. Los indicadores lanzan luz sobre la comprensión del campo científico sobre alfabetización en Brasil, en función de la identificación de algunas de sus raíces históricas.

\section{LETRAMIENTO・INVESTIGACIÓN・BIBLIOTECONOMÍA ・INDICADORES}


OS ÚLTIMOS ANOS, TEM SIDO CADA VEZ MAIOR A INSERÇÃO DA TEMÁTICA DO LETRAMENTO NA prática pedagógica, na formação de professores e na produção científica. O tema tem se tornado ainda mais abrangente pela transferência do conceito da área do ensino da leitura e da escrita para outras disciplinas, como a Matemática e o Design, por exemplo.

\begin{abstract}
$\mathrm{Na}$ contemporaneidade, percebe-se que a palavra letramento tornou-se abrangente, perpassando vários espaços da sociedade, presente em conversas informais entre professores, em documentos oficiais de instituições escolares, em artigos de revistas pedagógicas, em avaliações nacionais e internacionais de leitura e de escrita divulgadas pela mídia. (PICCOLI, 2010, p. 266)
\end{abstract}

Mortatti (1999, p. 20), ao discorrer sobre a implantação de novas crenças e metodologias no ensino e na pesquisa, levanta algumas questões: "Quando, por que, por quem e como se engendra, no Brasil, a tendência à definição de certos modelos de escolarização da leitura e escrita assim como de objetos e métodos de investigação relacionados a esse ensino?”. Esses questionamentos se fazem atuais e relevantes, justificando sua análise, uma vez que tais modelos definem e são definidos pela pesquisa sobre a temática do letramento e por seus pesquisadores, formando o que Bourdieu (1983) chamou de campo científico, estrutura que revela as posições, distribuições do poder, mudanças passadas, presentes e futuras dentro da academia, tendo em vista que os conflitos epistemológicos também são conflitos políticos.

\begin{abstract}
O universo "puro" da mais "pura" ciência é um campo social como outro qualquer, com suas relações de força e monopólios, suas lutas e estratégias, seus interesses e lucros, mas onde todas essas invariantes revestem formas específicas. (BOURDIEU, 1983, p. 122, grifo do autor)
\end{abstract}

Com o objetivo de lançar luz à compreensão do campo científico do letramento, este trabalho utiliza a análise bibliométrica, a fim de levantar indicadores de produção científica como forma de verificar o perfil das pesquisas de doutorado sobre a temática. A bibliometria se mostra como aporte consolidado teórica e metodologicamente para a descrição da evolução das pesquisas sobre letramento dentro da ciência brasileira. Entre as inúmeras aplicações da bibliometria, podemos citar: a seleção de livros e periódicos, a identificação de temas de pesquisa, o desenvolvimento de coleções, a quantidade e a qualidade das fontes, a formação de colégios invisíveis, o fator de imediatismo ou de impacto de artigos, cientistas e periódicos, a vida média da literatura, as razões de crescimento e declínio das áreas, etc. (SILVA; HAYASHI; HAYASHI, 2011). Dito de outro modo, a bibliometria se aplica à mensuração estatística de quaisquer tipos de registros do conhecimento, com o objetivo de observar os vínculos existentes entre a quantidade do que está registrado e quaisquer fenômenos que possam estar correlacionados.

Esta pesquisa é um estudo interdisciplinar entre as áreas de Educação, Linguística e Ciência da Informação: a Educação e a Linguística são áreas indissociáveis no estudo do ensino e da aprendizagem da leitura e da escrita, seja em contextos escolarizados ou não, já a Ciência da Informação fornece os aportes teórico-metodológicos para a criação de indicadores bibliométricos na observação da produção científica em qualquer campo do conhecimento. Ressalta-se que foi tomada como definição de interdisciplinaridade a concepção de Japiassu (1976), segundo o qual os 
estudos interdisciplinares não consistem em mera troca de dados para constituir um "empirismo compósito", mas sim na interação entre disciplinas, conceitos, diretrizes, procedimentos, epistemologia, esquemas conceituais, etc., os quais devem ser previamente comparados e julgados, apresentando um tríplice protesto contra: a) o saber fragmentado e fechado como o conhecimento verdadeiro; b) o divórcio entre universidade e a realidade dinâmica; e c) o conformismo diante do conhecimento imposto. Dessa forma, esta pesquisa buscou a interdisciplinaridade pela congregação mais profunda entre as três áreas, por meio da tentativa da utilização dos referenciais teóricos e metodológicos de uma área para a reflexão sobre as outras, resultando em um movimento de rompimento do conformismo imposto pela dicotomia dos saberes, em especial o descolamento da Ciência da Informação com as demais áreas, a qual, comumente, apenas provê os procedimentos metodológicos para a realização dos estudos bibliométricos.

\section{REFERENCIAL TEÓRICO}

A inserção do letramento no Brasil teve influência dos chamados Novos Estudos do Letramento, ou New Literacy Studies (NLS), os quais pretendiam diferenciar as práticas sociais de leitura e escrita do ensino da língua enquanto mera codificação e decodificação de uma tecnologia. Entretanto os pesquisadores de origem norte-americana e inglesa utilizam a expressão new literacy studies para se referir às práticas sociais de aprendizagem e literacy para a codificação e decodificação dos sinais gráficos da língua, enquanto os educadores brasileiros empregam o termo letramento no primeiro caso e o termo alfabetização no segundo.

No contexto brasileiro, o uso do termo letramento se deu justamente a fim de diferenciar os estudos que enfocam a leitura e a escrita enquanto práticas sociais dos trabalhos sobre alfabetização, os quais viam a língua como tecnologia que deve ser codificada (escrita) e decodificada (leitura). Considerando a ciência como um campo de disputas, conforme explica Bourdieu (2004), pode-se afirmar que a inserção da palavra letramento no Brasil foi capaz de iniciar a demarcação de um novo campo científico e advogar suas próprias bases epistemológicas, metodológicas e seus pesquisadores.

Soares (2016, p. 17) explica que: “Etimologicamente, a palavra literacy vem do latim litera (letra), com o sufixo -cy, que denota qualidade, condição, estado, fato de ser (como em innocency, a qualidade ou condição de ser inocente)", o que indica a qualidade de ser letrado, ou seja, aprender a ler e a escrever. O termo traz um sentido mais amplo do que alfabetizar, pois abarca o ensino da leitura e da escrita enquanto prática ao mesmo tempo dependente e determinante das interações sociais.

Implícita nesse conceito está a ideia de que a escrita traz consequências
sociais, culturais, políticas, econômicas, cognitivas, linguísticas, quer para o
grupo social em que seja introduzida, quer para o indivíduo que aprende a
usá-la. Em outras palavras: do ponto de vista individual, o aprender a ler e
a escrever - alfabetizar-se, deixar de ser analfabeto, tornar-se alfabetizado,
adquirir a "tecnologia" do ler e escrever e envolver-se nas práticas sociais
de leitura e de escrita - tem consequências sobre o indivíduo, e altera seu
estado ou condição em aspectos sociais, psíquicos, culturais, políticos,
cognitivos, linguísticos ou até mesmo econômicos [...]. (SOARES, 2016,
p. 17-18, grifos da autora)

De acordo com Street (2003), como o letramento não é uma habilidade técnica, e sim uma prática social, ele não pode ser neutro, sendo assim esses estudos representam uma mudança de abordagem quanto à natureza do ensino da leitura e da escrita. O letramento, segundo Street (2003), é uma prática social desde o princípio, cujos valores estão em jogo a partir do momento de sua promoção, não se tratando de uma simulação dentro das aulas de linguagens para um possível uso 
no futuro. As relações de poder que influenciam as práticas letradas também são influenciadas por elas e já estão presentes desde o momento em que se aprende a falar, a ler e a escrever, ou seja, muito antes do ingresso na escola.

O letramento ultrapassa o caráter individual da aprendizagem e toma o ensino da escrita como atividade que se constrói socialmente: "enquanto a alfabetização se ocupa da aquisição da escrita por um indivíduo, ou grupo de indivíduos, o letramento focaliza os aspectos sócio-históricos da aquisição de um sistema escrito por uma sociedade" (TFOUNI, 1995, p. 20).

Segundo Gee (2008), a pedagogia emancipatória de Paulo Freire está no cerne da ideia de que o ensino da leitura deve empoderar o ser humano para a compreensão de sua realidade social. O autor cita quatro pontos do livro Pedagogia do oprimido ${ }^{1}$ que têm relação intrínseca com o conceito de letramento: 1) o aprendizado envolve participação ativa, e não mera transmissão de informações do professor para o aluno; 2) ler a palavra e ler o mundo são tarefas interdependentes, pois fazer sentido na leitura pressupõe engajar o texto na realidade histórica; 3) o diálogo é fundamental na construção do aprendizado, pois as pessoas não aprendem sozinhas, conforme suas habilidades individuais, e os textos não estão isolados entre si e da estrutura social; 4) a política é parte integrante do processo, pois ler o mundo presume que há diferentes formas de interpretá-lo, as quais variam conforme sua posição na hierarquia social.

Entretanto a separação entre o ensino do código e as práticas sociais de escrita não se dá no sentido de serem instâncias estanques, mas aspectos congruentes na aprendizagem da língua. Por isso, é importante ressaltar que os usos sociais da leitura e da escrita não pretendem substituir o aprendizado do uso do código linguístico, sendo "possível e indispensável a presença da associação desses dois processos para que a escola garanta a apropriação do sistema alfabético e ortográfico" (MONTEIRO, 2010, p. 25).

Pode-se afirmar que não existe um modelo de letramento universal e atemporal a ser criado e utilizado, o qual só seria possível se fosse neutro; as práticas sociais de leitura e escrita são tão dinâmicas quanto a história, ou seja, quanto todas as transformações sociais, culturais, políticas, econômicas, tecnológicas, etc.

Deve-se ressaltar que não se pretende esgotar o assunto letramento, tendo em vista que não há uma definição fechada para o termo, de tal modo que Geraldi (2014) afirma que sua conceituação é gaseificada, pois se refere a uma variedade de fenômenos tão ampla e a uma expansão a outras áreas tão veloz que se tornou epistemologicamente problemático defini-lo. Como o tema é muito amplo e complexo, acredita-se que o mapeamento do perfil das teses sobre letramento possa ajudar a delinear sua configuração dentro da ciência brasileira.

\section{PROCEDIMENTOS METODOLÓGICOS}

Esta pesquisa realizou a análise bibliométrica de 237 teses sobre letramento, a fim de levantar o perfil dos trabalhos de doutorado realizados em duas décadas sobre o tema. A pesquisa, em relação a seus objetivos, é exploratória e descritiva, pois visa a descrever as características de uma população de pesquisadores da área, caracterizando-se pela utilização de coleta de dados por intermédio de técnicas padronizadas (GIL, 2002). Quanto aos procedimentos técnicos, o estudo se baseia na ex-post facto (a partir do fato passado), pois pretende verificar a existência de relações entre variáveis de fatos ocorridas no passado (GIL, 2002, p. 49), por intermédio de técnicas e métodos predeterminados, no caso a bibliometria.

A bibliometria remonta a 1890 e foi inicialmente utilizada para o apoio à gestão de bibliotecas como meio de avaliar a circulação de livros, tendo sido transposta, mais tarde, para a mensuração da própria produção científica como suporte à tomada de decisões: 
O objetivo da bibliometria é fornecer uma ideia do estado da arte e da evolução da ciência, da tecnologia e do conhecimento e nesse sentido é mais que uma lista de referências de trabalhos utilizados, fornecendo um quadro dos temas de pesquisa que entusiasmam os pesquisadores e dão uma ideia do conteúdo e da estrutura da pesquisa. (HAYASHI, 2007, p. 95, grifo do autor)

Ressalta-se que o levantamento de indicadores bibliométricos não pretende avaliar a qualidade dos trabalhos analisados, mas utilizar a produção científica como fenômeno que ajuda a descrever o comportamento de uma dada área ou comunidade científica.

Como fonte de dados, foi utilizada a Biblioteca Digital Brasileira de Teses e Dissertações (BDTD), repositório digital coordenado pelo Instituto Brasileiro de Informação em Ciência e Tecnologia (Ibict), cujo objetivo é possibilitar a publicação de teses e dissertações nacionais e estrangeiras.

Para a recuperação de dados, foi empregada a busca avançada, agregando-se os termos letramento, literacia e multiletramentos no campo assunto e selecionando a correspondência de busca "qualquer termo". Dessa forma, chegou-se à expressão:

\section{(Assunto:letramento OU Assunto:literacia OU Assunto:multiletramentos)}

Não foi utilizado letramentos, pois o termo no singular também recupera a palavra no plural. Foram aplicados os filtros teses, língua portuguesa e data de 1997 a 2016, a fim de recuperar apenas os trabalhos de doutorado publicados em português, excluindo teses em outros idiomas. O intervalo entre os anos 1997 e 2016 se deu a fim de abranger 20 anos a partir da data em que a coleta foi realizada (entre os dias 3 e 7 de julho de 2017). Ressalta-se que a tese mais antiga sobre o tema letramento na BDTD data exatamente de 1997, ou seja, houve coincidência entre o primeiro ano abrangido pelo intervalo e a primeira tese publicada. Optou-se pelo intervalo de duas décadas, pois se julgou que um período menor englobaria um corpus muito pequeno, já um intervalo maior poderia gerar uma extensão muito grande de dados. Foram excluídas as dissertações do corpus, sendo utilizadas apenas as teses, tendo em vista que as pesquisas de doutorado são trabalhos de cunho inédito e possuem maior densidade teórica e maturidade metodológica.

À época da coleta, foram recuperados 250 registros, entretanto foram excluídos 13 que não abordavam os aspectos sociais do ensino da leitura e da escrita, chegando-se a um corpus de pesquisa de 237 trabalhos de doutorado. Para essa exclusão, foi realizada a leitura técnica das teses, utilizando-se os procedimentos de Análise Documental de textos científicos já consolidados na Ciência da Informação. A Análise Documental, atividade de base interdisciplinar fundamentada na Lógica e na Linguística, é um processo de leitura estratégica e não linear de partes representativas dos documentos, com vistas à identificação, seleção e descrição de assuntos, métodos e variáveis importantes dos textos.

Foram consideradas para análise as variáveis: a) evolução temporal; b) distribuição geográfica e institucional; c) orientação e gênero; e d) uso de palavras-chave. Este último indicador não será discutido neste artigo, devido a limitações de tamanho impostas pelas publicações periódicas. Com o auxílio do software Excel $^{\circledR}$, foi elaborada uma planilha de coleta e registro dos dados contendo os campos: código, autor, gênero do autor, orientador, gênero do orientador, título do trabalho, ano de defesa, instituição de ensino, programa de pós-graduação, dependência administrativa, região do país, agência de fomento e palavras-chave. Após a coleta, os dados foram transportados para o VantagePoint ${ }^{\circledR}$, software de análise bibliométrica que possibilita a mensuração estatística de conjunto de dados. 


\section{RESULTADOS E DISCUSSÃO}

Ressalta-se que não foram identificados trabalhos correlatos a esta pesquisa, seja quanto a recorte temporal, bases de dados analisadas ou procedimentos. As pesquisas mais próximas são do tipo estado da arte, já os trabalhos bibliométricos encontrados se debruçam em subtemas, como letramento digital, letramento informacional e letramento científico, por exemplo, como é o caso das pesquisas de Serrano (2010), Oliveira (2015), Gonçalves (2018) e Almeida (2018).

O Centro de Alfabetização, Leitura e Escrita (Ceale) realiza o projeto de pesquisa "Alfabetização no Brasil: o estado do conhecimento (Abec)", contando com a participação de pesquisadores de oito instituições de ensino superior (IES). Os currículos Lattes de todos os 10 pesquisadores que pertencem à coordenação do projeto foram consultados, notando-se que Iole Trindade realizou subprojeto focado na produção científica sobre letramento, mas abrangeu apenas o estado do Rio Grande do Sul (ITAQUI; TRINDADE, 2007; TRINDADE; ITAQUI; COSTA, 2007; SPERRHAKE; TRINDADE, 2009). Dentre os pesquisadores do projeto Abec, a produção de Maria do Rosário Longo Mortatti e Francisca Izabel Pereira Maciel, apesar de enfocar a alfabetização, possui recorte temporal maior e discute a questão da produção científica, por isso algumas obras das autoras dialogaram com os dados desta pesquisa (MORTATTI, 2014; MORTATTI; OLIVEIRA; PASQUIM, 2014).

\section{PERFIL DAS TESES: DISTRIBUIÇÃO TEMPORAL E GEOGRÁFICA}

A Figura 1 mostra a evolução temporal das teses entre 1997 e 2017; os dados de 2017 (barra cinza na figura delimitada pelo traço vertical pontilhado) não foram abarcados pelo recorte da pesquisa, entretanto considerou-se necessário inserir dados mais atuais, a fim de contestar uma possível tendência de declínio no futuro de teses sobre a temática sugerida pela Figura 1, tendo em vista que houve queda de 36 trabalhos em 2015 para 17 em 2016.

Observou-se aumento significativo de defesas de teses sobre letramento entre 2003 e 2015, com um pico de produções em 2015. Das 237 teses, 88,6\% $(\mathrm{n}=210)$ foram defendidas nos últimos dez anos (2007 a 2016). A maior parte dos trabalhos foi defendida nos anos de 2015 (15,19\%), 2013 $(12,66 \%)$ e 2014 (12,66\%).

FIGURA 1

EVOLUÇÃO TEMPORAL DAS TESES NA BDTD ENTRE 1997 E 2017

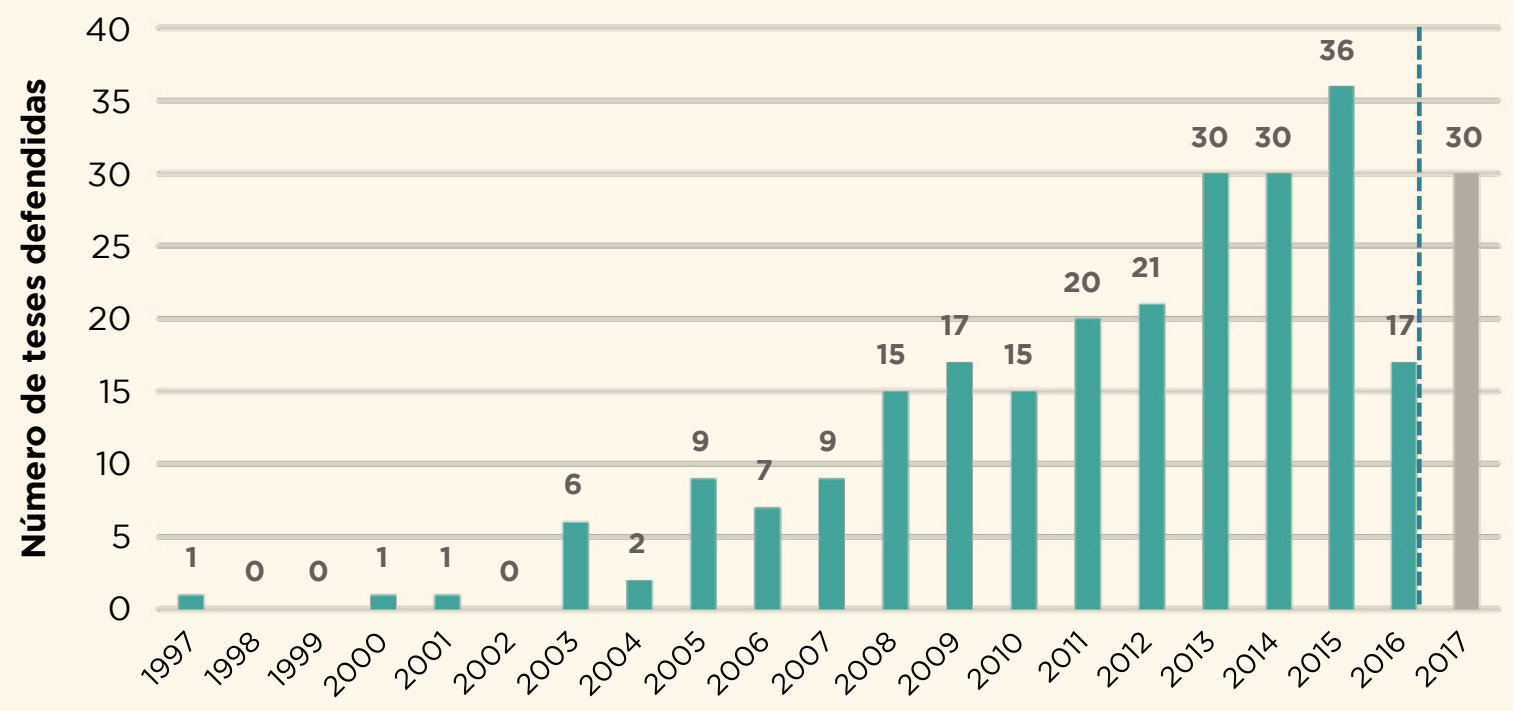

\section{Ano das defesas}


A evolução temporal pode ser dividida em duas fases: uma primeira, de incipiência do tema, que vai de 1997 a 2004, em que a produção é muito próxima de 1 (com 11 defesas no período), e a segunda, que vai de 2005 a 2016, em que se nota o aumento do interesse pela temática (com 226 defesas no período). Maciel (2014) já havia apontado para a tendência de crescimento de pesquisas com enfoque no letramento como subtema dentro de trabalhos sobre alfabetização: dentre as 1.621 teses e dissertações recuperadas pela autora no Portal de Teses da Capes em 2013, 106 trabalhos explicitavam o letramento como objeto de pesquisa.

Pode-se dizer que o crescimento dos trabalhos se iniciou em 2003, adquirindo tendência ao crescimento em 2005. Das 6 teses defendidas em 2003, 3 são da Universidade Estadual de Campinas (Unicamp), o que indica o pioneirismo dessa IES no interesse pela temática.

Ressalta-se que a queda nas defesas em 2016 é um fenômeno atípico e não deve indicar falta de interesse pelo tema, pois verificou-se que houve aumento do número de teses sobre letramento na BDTD no ano de 2017, retomando o patamar de produção de 2014.

Tendo em vista que uma pesquisa de doutorado deve ser desenvolvida, idealmente, em quatro anos, os doutorandos que defenderam em 2003/2005 devem ter ingressado entre 1999 e 2002. Mas pode-se afirmar que o interesse desses doutores pelo letramento se deu antes desse período, pois foram necessários alguns anos para que se apropriassem do tema, ou seja, o motivo do início desse aumento das defesas se deu na segunda metade da década de 1990 e suas prováveis causas remetem a mudanças profundas ocorridas na educação à época.

Na década de 1980, houve a inserção da temática do letramento entre educadores e pesquisadores brasileiros; já o ano de 1990 foi escolhido pela Organização das Nações Unidas para a Educação, a Ciência e a Cultura (Unesco) para ser o Ano Internacional da Alfabetização. No Brasil, a década de 1990 foi marcada por algumas reformas da educação básica, podendo ser destacados, em ordem cronológica: a implementação do Sistema de Avaliação da Educação Básica (Saeb) em 1990, a promulgação da nova Lei de Diretrizes e Bases da Educação Nacional (Lei n. 9.394) em 1996, alterações profundas na operacionalização do Programa Nacional de Avaliação Permanente do Livro Didático (PNLD) em 1997, a publicação dos Parâmetros Curriculares Nacionais (PCN) para o Ensino Fundamental em 1997, o Exame Nacional do Ensino Médio (Enem) em 1998 e os Parâmetros Curriculares Nacionais para o Ensino Médio em 1999. Tais reformas trouxeram nova luz ao ensino da leitura e da escrita, em especial a prescrição de se trabalhar com a diversidade de gêneros textuais, um dos fundamentos dos estudos do letramento. Monteiro (2010, p. 22) explica que algumas iniciativas visaram a propor alternativas de diminuição do fracasso escolar, como o PCN, a LDB e a própria constituição de 1988, "que instituiu o voto facultativo ao analfabeto e estabeleceu diretrizes para eliminar o analfabetismo [...]”.

Segundo Maciel (2014, p. 118), a produção científica sobre alfabetização nas décadas de 1970 e 1980 focava nas análises sobre fracasso do sistema escolar, mas "nada acrescentava, a não ser repetir as mesmas críticas já conhecidas [...]”. Já a partir dos anos de 1990, concepções advindas da Linguística, Sociolinguística, Psicologia e Antropologia e as mudanças nas políticas educacionais trouxeram reflexões sobre o próprio sentido da alfabetização e da leitura.

Em relação à ascensão de temáticas na academia, este trabalho parte do pressuposto de que o crescimento da produção sobre determinado tema não deve ser avaliado considerando-se exclusivamente o aumento do interesse e do alcance de uma temática, mas também pela ótica da ampliação dos programas de pós-graduação.

Notou-se, na década de 1990, expansão da pós-graduação brasileira, tendo entre os principais fatores a instituição da Coordenação de Aperfeiçoamento de Pessoal em Nível Superior (Capes) como fundação pública (Lei n. 8.405, de 9 de janeiro de 1992) e sua posterior reestruturação, a fim de abarcar a responsabilidade de avaliar os cursos stricto sensu (NOBRE; FREITAS, 2017). No fim dos anos de 1990, foi implementado o novo modelo de avaliação, deslocando a valorização da docência para a pesquisa e introduzindo o conceito de programas de pós-graduação (LIEVORE; PICININ; PILATTI, 2017). 
É notório o crescimento da pós-graduação nessa época, passando de 1.971 cursos stricto sensu em 1995 para 2.621 em 2000, segundo dados do Sistema de Informações Georreferenciadas da Capes (GEOCAPES, 2018), ou seja, uma expansão de 32,98\% em cinco anos. As áreas de Letras e Linguística e Educação tiveram aumento de cursos stricto sensu entre 1998 e 2017 da ordem de, respectivamente, $276,79 \%$ e $488,89 \%$. As duas áreas reúnem $90,28 \%$ do corpus analisado nesta pesquisa, como será descrito posteriormente.

Se entre 1998 e 2016 o número de programas de pós-graduação tivesse se mantido igual, seria mais simples estabelecer a relação entre crescimento do interesse sobre letramento na academia e número de teses publicadas, entretanto, não se pode deixar de considerar que a expansão dos cursos de doutorado abre espaço para essa ampliação. Se há aumento na produção científica sobre certo assunto, mas não há aumento na quantidade nas vagas nos cursos stricto sensu, então outros temas deverão ceder espaço aos emergentes, podendo-se notar um crescimento simples baseado na transposição de interesse de um tema para outro.

Foram verificadas as regiões geográficas em que as teses foram desenvolvidas. Quanto à distribuição por região, 51,48\% ( $\mathrm{n}=122)$ das teses defendidas foram desenvolvidas no Sudeste, 22,78\% ( $\mathrm{n}=54)$ no Sul, $13,08 \%(\mathrm{n}=31)$ no Centro-Oeste e $12,66 \%(\mathrm{n}=30)$ no Nordeste, sendo que não houve trabalhos publicados sobre letramento na região Norte do país.

Em pesquisa sobre o estado da arte sobre alfabetização, Mortatti, Oliveira e Pasquim (2014) apontaram que $70 \%$ das teses sobre o tema defendidas entre 1970 e 2011 pertenciam à região Sudeste do Brasil, sendo que quase metade foi defendida entre 2000 e 2009. Os autores já haviam destacado o crescimento da produção nas regiões Sul e Nordeste e que nenhum trabalho de doutorado havia sido defendido na região Norte. Tendo em vista que o letramento é uma temática que se originou da ampliação do olhar sobre a alfabetização, pode-se dizer que os dados levantados por Mortatti, Oliveira e Pasquim (2014) corroboram com os encontrados nesta pesquisa, indicando um desequilíbrio nas pesquisas sobre o ensino da leitura e da escrita.

Segundo Maroldi (2017), que realizou estudos bibliométricos sobre educação indígena, apesar da expansão da pós-graduação em Educação nas regiões Norte e Nordeste do Brasil entre os anos de 1990 e 2000, não tem ocorrido aproximação da produção científica dessas regiões aos patamares de trabalhos de mestrado e doutorado dos estados do Sudeste e Sul.

No ano de 2011, dos 4.650 cursos de pós-graduação, 51\% se encontravam no Sudeste, $20 \%$ no Sul, $18 \%$ no Nordeste, 7,2\% no Centro-Oeste e $4 \%$ no Norte (CIRANI; CAMPANARIO; SILVA, 2015). Esses números se aproximam às proporções de teses sobre letramento encontradas nesta pesquisa, o que corrobora com a ideia de que a distribuição de vagas na pós-graduação pode influenciar a distribuição regional das temáticas de pesquisa.

Ao avaliar a produção por unidade federativa, nota-se que as teses estão concentradas em apenas 13 estados e no Distrito Federal, como pode ser visto na Tabela 1, ou seja, 13 estados da federação (50\%) não apresentaram pesquisa de doutorado sobre letramento entre 1997 e 2016 na BDTD. Nas regiões Sudeste e Sul, todos os estados tiveram produção sobre o tema.

O estado de São Paulo mostra a maior concentração de teses, com 40,08\% ( $\mathrm{n}=95)$ dos trabalhos, seguido pelo Rio Grande do Sul, com 13,92\% ( $n=33$ ) e pelo Distrito Federal, com 12,66\% ( $n=30$ ). 
TABELA 1

DISTRIBUIÇÃO DAS TESES POR UNIDADE FEDERATIVA ENTRE 1997 E 2016

\begin{tabular}{lcccc}
\hline UNIDADE FEDERATIVA & REGIÃO & POSIÇÃO & QUANTIDADE & $\%$ \\
\hline São Paulo & SE & 1 & 95 & 40,08 \\
\hline Rio Grande do Sul & S & 2 & 33 & 13,92 \\
\hline Distrito Federal & DF & 3 & 30 & 12,66 \\
\hline Minas Gerais & SE & 4 & 18 & 7,59 \\
\hline Ceará & NE & 5 & 13 & 5,49 \\
\hline Paraná & S & 6 & 12 & 5,06 \\
\hline Rio Grande do Norte & NE & 7 & 10 & 4,22 \\
\hline Rio de Janeiro & SE & 8 & 9 & 3,80 \\
\hline Santa Catarina & S & 9 & 8 & 3,38 \\
\hline Pernambuco & NE & 10 & 4 & 1,69 \\
\hline Paraíba & NE & 11 & 2 & 0,84 \\
\hline Espírito Santo & SE & 12 & 1 & 0,42 \\
Goiás & CO & 12 & 1 & 0,42 \\
\hline Bahia & NE & 12 & 1 & 0,42 \\
\hline Total & -- & -- & 237 & 100,00 \\
\hline
\end{tabular}

Fonte: Elaboração da autora com dados da pesquisa.

Em se tratando de diferenças regionais, não se pode desconsiderar a taxa populacional dos estados. Segundo Cirani, Campanario e Silva (2015), há uma razão entre população e número de cursos; entretanto, a taxa de crescimento de cursos é inversa à renda per capita: em 2000, havia 22,9 cursos por 100 mil habitantes no Sudeste e 2,8 no Norte; já em 2010, a região Sudeste perdeu a liderança para o Sul, que tinha 29,5 para cada 100 mil habitantes, e a região Norte subiu para 12,2.

\section{INSTITUIÇÕES ENVOLVIDAS: AFILIAÇÃO DAS TESES, PROGRAMAS DE PÓS-GRADUAÇÃO E INSTITUIÇÕES DE FOMENTO}

Verificou-se o desenvolvimento de pesquisas de doutorado sobre letramento em 27 IES, figurando no topo da lista, com mais de 20 teses defendidas: Unicamp (18,99\%), Universidade de São Paulo (USP) (12,66\%), Universidade de Brasília (UnB) (12,66\%) e Universidade Federal do Rio Grande do Sul (UFRGS) (9,28\%), como detalhado na Tabela 2. Dessa forma, percebeu-se que 53,59\% ( $\mathrm{n}=127)$ da produção sobre letramento está concentrada em 4 instituições. Por outro lado, notou-se que 37\% das IES $(\mathrm{n}=10)$ produziram apenas 1 tese sobre a temática cada.

A Tabela 2 apresenta o ranque das IES de afiliação das teses defendidas, sendo que instituições que tiveram a mesma quantidade de trabalhos figuram na mesma posição (por isso apenas 14 posições). 
TABELA 2

INSTITUIÇÕES DE ENSINO SUPERIOR DE AFILIAÇÃO DAS TESES

\begin{tabular}{|c|c|c|c|}
\hline IES & POSIÇÃO & TRABALHOS & $\%$ \\
\hline Unicamp & 1 & 45 & 18,99 \\
\hline USP & 2 & 30 & 12,66 \\
\hline UnB & 2 & 30 & 12,66 \\
\hline UFRGS & 3 & 22 & 9,28 \\
\hline UFMG & 4 & 17 & 7,17 \\
\hline PUC-SP & 5 & 13 & 5,49 \\
\hline UFC & 5 & 13 & 5,49 \\
\hline UFRN & 6 & 10 & 4,22 \\
\hline UEL & 7 & 9 & 3,8 \\
\hline UFSC & 8 & 8 & 3,38 \\
\hline UCPEL & 9 & 7 & 2,95 \\
\hline PUC-Rio & 10 & 5 & 2,11 \\
\hline Unesp & 10 & 5 & 2,11 \\
\hline Uerj & 11 & 4 & 1,69 \\
\hline UFPE & 11 & 4 & 1,69 \\
\hline UFPR & 12 & 3 & 1,27 \\
\hline UFPB & 13 & 2 & 0,84 \\
\hline Mackenzie-SP & 14 & 1 & 0,42 \\
\hline UCS e UniRitter & 14 & 1 & 0,42 \\
\hline UFBA & 14 & 1 & 0,42 \\
\hline Ufes & 14 & 1 & 0,42 \\
\hline UFG & 14 & 1 & 0,42 \\
\hline UFJF & 14 & 1 & 0,42 \\
\hline UFPEL & 14 & 1 & 0,42 \\
\hline UFSCar & 14 & 1 & 0,42 \\
\hline UFSM & 14 & 1 & 0,42 \\
\hline Unisinos & 14 & 1 & 0,42 \\
\hline Total & -- & 237 & 100,00 \\
\hline
\end{tabular}

Fonte: Elaboração da autora com dados da pesquisa.

Destaca-se a importância do Programa de Pós-graduação em Linguística Aplicada da Unicamp, onde foram defendidas 34 teses, ou seja, 14,35\% do total. Juntas, Unicamp, USP, UnB e UFRGS abarcam $53,59 \%(n=127)$ das pesquisas sobre letramento; as demais 23 instituições representam 46,41\% $(\mathrm{n}=110)$ das teses. Portanto, nota-se, em uma ponta, concentração de trabalhos em apenas 4 instituições e, na outra, dispersão da produção de teses.

Segundo Pietrucha (2018), que analisou os fatores que afetam a posição das universidades em ranques mundiais, são determinantes as variáveis: tamanho da economia, nível de desenvolvimento econômico, gastos com pesquisa e desenvolvimento, estabilidade política em longo prazo e qualidade individual das instituições. Sugere-se que sejam feitos estudos para verificar se as variáveis interferem no posicionamento de cada estado e IES no ranque da produção científica de teses sobre letramento.

O tamanho da economia diz respeito ao Produto Interno Bruto (PIB), ao nível de desenvolvimento econômico, a investimentos e à proporção de PIB per capita (PIETRUCHA, 2018). Tomando como exemplo os estados com maior PIB no Brasil, encontram-se São Paulo (32,40\% do PIB) e Rio de Janeiro (11\% do PIB). São Paulo aparece em primeiro lugar na produção de teses sobre letramento (40,08\%), já o Rio de Janeiro consta em oitava posição (3,8\%). Tendo em vista a variável 
estabilidade política em longo prazo, os dois estados possuem situações diferentes. O estado paulista tem passado por uma estabilidade de políticas. Não adentrando nas críticas à política educacional do governo do Partido da Social Democracia Brasileira (PSDB), como a predominância da lógica de mercado (SANFELICE, 2010), o partido, que está no poder desde 1995 e logrou eleger governador para o mandato 2019-2022, marca uma fase de constância de atos e decisões.

Já o Rio de Janeiro tem passado por grande instabilidade política nas duas últimas décadas, com multiplicação de casos de corrupção que resultaram na prisão de dois ex-governadores, perdas fiscais em decorrência da crise na Petrobras, responsável por grande parte da receita fluminense, resultando no pacote de austeridade, com proposta de aumento de impostos e desconto de 30\% dos salários de servidores e de pensões, além da aprovação e posterior prorrogação de estado de calamidade pública (FERREIRA; BARREIRA, 2017).

As discrepâncias na produção científica entre as regiões geográficas e as IES, como notadas nas Tabelas 1 e 2 , são fruto do individualismo da distribuição das pesquisas das agendas institucionais, conforme mencionado por Cirani, Campanario e Silva (2015), e não de um plano nacional de pesquisa. Tendo em vista os problemas históricos de deficiência no ensino da leitura e escrita no país inteiro, não deveria haver um incentivo estratégico às pesquisas na área que as distribuíssem entre as regiões de modo mais uniforme de acordo com a densidade demográfica e as necessidades levantadas pela própria academia e pelos sistemas de ensino?

Mortatti (2014) questiona se a definição de temas, problemas e métodos nas pesquisas sobre ensino da leitura e escrita é fruto de modismo ou advém de necessidades surgidas em decorrência de políticas públicas. No caso de as políticas públicas funcionarem como mediadoras, influenciando a agenda dos pesquisadores, a autora pergunta como deve ser o impacto reverso. Os dados deste trabalho permitem afirmar que o impacto das políticas se restringe a prescrever fundamentos teóricos e didáticos e a insurgir temas e problemas, mas não opera no sentido de colocar as pesquisas como estratégia para cumprir com as políticas. Não se trata de ferir a autonomia dos cientistas, mas de lançar incentivos alinhados às necessidades educacionais. Não seria o caso de promover, como diz Bourdieu (2004), a ciência pura, totalmente livre da atenção às necessidades sociais, ou a ciência escrava, sujeita às demandas políticas, mas sim de instaurar uma ciência engajada em um projeto de letramento e em um projeto científico para o país.

Dentre as 27 IES, 48,52\% ( $n$ = 115) são federais, 39,66\% ( $n=94)$ são estaduais, 8,86\% são privadas ( $\mathrm{n}=21)$ e $2,95 \%$ ( $\mathrm{n}=7$ ) são comunitárias, o que reforça a importância da universidade pública na ciência brasileira, pois $88,18 \%(n=209)$ dos trabalhos foram desenvolvidos em IES públicas.

Entretanto, a presença maciça das universidades públicas possui uma outra faceta: a da produtividade. Ou seja, há relação direta entre o número de orientadores, a quantidade de trabalhos defendidos e a qualidade das notas recebidas na avaliação da Capes, a qual:

[...] é feita com certa fragilidade, considerando indicadores externos de qualidade que são discutíveis (composição das bancas examinadoras, quantidade de dissertações e teses por docente orientador, concentração de orientação de dissertações e teses em alguns orientadores, tempo de conclusão, vinculação às linhas de pesquisa). Em alguns programas o volume de dissertações e teses é muito superior ao de publicações, evidenciando que parte expressiva da produção não é submetida à publicação ou não é aprovada para tal finalidade. (GUIMARÃES et al., 2015, p. 110)

Mortatti (2014) questiona a qualidade das pesquisas sobre alfabetização diante do produtivismo. Segundo a autora, pressões externas em relação à produção científica trazem o risco de que os pesquisadores deixem em segundo plano os questionamentos necessários ao trabalho científico e operem um fazer mecânico que se torna uma reprodução geradora de verdades inquestionáveis, atemporais e a-históricas. 
Foram verificados a quais programas de pós-graduação as teses estão vinculadas. Houve produção de teses sobre letramento em 26 programas de pós-graduação, com concentração em programas de Educação $(29,97 \%)(n=71)$, Linguística Aplicada $(21,94 \%)(n=52)$, Linguística $(14,77 \%)$ $(n=35)$ e Letras $(12,24 \%)(n=29)$, como mostra a Tabela 3. Para a indicação da área de avaliação, foi utilizada a delimitação da Capes (2017).

TABELA 3

PROGRAMAS DE PÓS-GRADUAÇÃO

\begin{tabular}{|c|c|c|c|}
\hline $\begin{array}{l}\text { GRANDE ÁREA DE } \\
\text { AVALIAÇÃO }\end{array}$ & PROGRAMA DE PÓS-GRADUAÇÃO & QUANTIDADE & $\%$ \\
\hline \multirow{2}{*}{ Educação } & Educação & 71 & 29,97 \\
\hline & Educação Brasileira & 1 & 0,42 \\
\hline \multirow{2}{*}{ Ensino } & Educação Matemática & 4 & 1,70 \\
\hline & Educação Científica e Tecnológica & 1 & 0,42 \\
\hline \multirow{12}{*}{ Letras/Linguística } & Linguística Aplicada & 52 & 21,94 \\
\hline & Linguística & 35 & 14,77 \\
\hline & Letras & 29 & 12,24 \\
\hline & Estudos da Linguagem & 8 & 3,38 \\
\hline & Estudos Linguísticos e Literários de Inglês & 7 & 2,95 \\
\hline & Estudos da Tradução & 2 & 0,84 \\
\hline & Estudos Linguísticos & 2 & 0,84 \\
\hline & Filologia e Língua Portuguesa & 2 & 0,84 \\
\hline & Linguística Aplicada e Estudos da Linguagem & 2 & 0,84 \\
\hline & Letras e Linguística & 1 & 0,42 \\
\hline & Língua Portuguesa & 1 & 0,42 \\
\hline & Literatura & 1 & 0,42 \\
\hline \multirow{2}{*}{ Comunicação e Informação } & Ciências da Comunicação & 2 & 0,84 \\
\hline & Ciência da Informação & 2 & 0,84 \\
\hline \multirow{2}{*}{ Artes } & Artes & 1 & 0,42 \\
\hline & Artes visuais & 1 & 0,42 \\
\hline \multirow{2}{*}{ Interdisciplinar } & Informática na Educação & 4 & 1,70 \\
\hline & Educação, Arte e História da Cultura & 1 & 0,42 \\
\hline \multirow[b]{2}{*}{ Psicologia } & Psicologia & 5 & 2,11 \\
\hline & Processos de Desenvolvimento Humano e Saúde & 1 & 0,42 \\
\hline Serviço Social & Serviço Social & 1 & 0,42 \\
\hline Total & -- & 237 & 100,00 \\
\hline
\end{tabular}

Fonte: Elaboração da autora com dados da pesquisa.

Percebe-se que 90,28\% ( $n=214$ ) das teses foram desenvolvidas em programas de pós-graduação avaliados em duas grandes áreas: 59,90\% ( $\mathrm{n}=142)$ na área de Letras/Linguística e 30,38\% ( $\mathrm{n}=72)$ na área de Educação. Nota-se a presença de trabalhoss em 8 grandes áreas de avaliação e 26 programas de pós-graduação diferentes, indicando a abrangência da temática para especialidades diferenciadas, como Artes e Psicologia.

Tem sido comum encontrar na literatura científica trabalhos sobre letramento que não fazem parte da esfera da aprendizagem da leitura e da escrita, como alfabetização científica, letramento matemático, letramento digital, etc. Cabe aqui o alerta de Cerutti-Rizzatti (2012), segundo a qual o termo letramento é empregado erroneamente em alguns trabalhos como sinônimo de "processo cultural", sendo preciso avaliar a apropriação do conceito nas diversas disciplinas, a fim de identificar qual sentido é dado para letramento nessas pesquisas. 
Em relação às bolsas de pesquisa, 48,95\% $(\mathrm{n}=116)$ dos pesquisadores não receberam fomento e 51,05\% ( $\mathrm{n}=121)$ tiveram auxílio financeiro, figurando como principais agências a Capes, com 29,11\% ( $n=69$ ), e o Conselho Nacional de Desenvolvimento Científico e Tecnológico (CNPq), com $10,97 \%(n=26)$, como mostra a Tabela 4.

\section{TABELA 4}

FOMENTO ÀS PESQUISAS DE DOUTORADO SOBRE LETRAMENTO

\begin{tabular}{|c|c|c|}
\hline AGÊNCIA DE FOMENTO & QUANTIDADE & $\%$ \\
\hline Sem bolsa & 116 & 48,95 \\
\hline Capes & 69 & 29,11 \\
\hline CNPq & 26 & 10,98 \\
\hline Fapemig & 4 & 1,70 \\
\hline Fapesp & 3 & 1,27 \\
\hline Funcap & 3 & 1,27 \\
\hline Capes Reuni & 2 & 0,84 \\
\hline CNPq/Faep & 1 & 0,42 \\
\hline Elap & 1 & 0,42 \\
\hline Fapeam & 1 & 0,42 \\
\hline Fapemig/Capes & 1 & 0,42 \\
\hline Fapesp/Capes & 1 & 0,42 \\
\hline Fundação Ford & 1 & 0,42 \\
\hline Fundect/Elap & 1 & 0,42 \\
\hline Graduate Students Exchange Program & 1 & 0,42 \\
\hline IPM (Instituto Presbiteriano Mackenzie) & 1 & 0,42 \\
\hline PAC-DT/Uneb & 1 & 0,42 \\
\hline PUC-SP & 1 & 0,42 \\
\hline SEE/SP & 1 & 0,42 \\
\hline Uepa & 1 & 0,42 \\
\hline UOL Bolsa Pesquisa & 1 & 0,42 \\
\hline Total & 237 & 100,00 \\
\hline
\end{tabular}

Fonte: Elaboração da autora com dados da pesquisa.

Percebe-se a importância da esfera federal para a promoção de pesquisas sobre letramento; somando os auxílios da Capes e do CNPq, nota-se que 42,08\% ( $\mathrm{n}=95)$ das teses receberam auxílio financeiro de órgãos federais. Nas últimas décadas, ocorreu um expressivo crescimento de investimentos: a distribuição de bolsas de doutorado nas Ciências Humanas aumentou de 1.679 em 1997 para 5.968 em 2016; já na área de Linguística, Letras e Artes, passou de 487 em 1997 para 2.078 em 2016 (GEOCAPES, 2018).

Comparando esses dados a outros levantamentos bibliométricos em bases de teses e dissertações, percebe-se que a distribuição de bolsas em outras subáreas dentro da Educação é, em sua maioria, menor: apenas 33,34\% receberam bolsa na História da Educação (CADAMURO, 2011), 50\% na Sociologia da Educação (SILVA, 2013) e 28\% na Educação de Surdos (RAMOS, 2017).

Segundo dados do Plano Nacional de Pós-graduação (PNPG) (2011-2020) (BRASIL, 2010), 45,5\% dos doutorandos no Brasil recebem fomento à pesquisa. Portanto, considera-se positivo o fato de o auxílio ter sido concedido a 51,05\% dos autores das teses sobre letramento, especialmente tendo em vista que a crescente pressão para a mercantilização da ciência brasileira sacrifique as Ciências Humanas. 


\section{PESSOAS ENVOLVIDAS: ORIENTAÇÃO E GÊNERO}

Foi feito levantamento acerca da orientação das teses sobre letramento, a fim de indicar a frente de pesquisa dos orientadores, sua afiliação institucional e perfil acadêmico. Os 237 trabalhos foram orientados por 150 orientadores, como pode ser visto na Tabela 5. A professora Stella Maris Bortoni-Ricardo (UnB) orientou 5,49\% dos trabalhos ( $\mathrm{n}=13$ ), seguida pelas professoras Angela Kleiman (Unicamp) com 5,06\% ( $n=12)$, Maria Izabel Santos Magalhães (UnB) com 3,38\% ( $n=8)$, Walkyria Maria Monte Mór (USP) com 3,38\% ( $\mathrm{n}=8)$ e Maria do Socorro Oliveira (UFRN) com 2,53\% $(\mathrm{n}=6)$ das orientações.

TABELA 5

\section{ORIENTADORES DAS PESQUISAS E FRENTE DE ORIENTADORES}

\begin{tabular}{|c|c|c|c|}
\hline ORIENTADOR & IES & QUANTIDADE & $\%$ \\
\hline Stella Maris Bortoni-Ricardo & UnB & 13 & 5,49 \\
\hline Angela Kleiman & Unicamp & 12 & 5,06 \\
\hline Maria Izabel Santos Magalhães & UnB & 8 & 3,38 \\
\hline Walkyria Maria Monte Mór & USP & 8 & 3,38 \\
\hline Maria do Socorro Oliveira & UFRN & 6 & 2,53 \\
\hline Raquel Salek Fiad & Unicamp & 5 & 2,12 \\
\hline Luciene Juliano Simões & UFRGS & 4 & 1,70 \\
\hline Maria das Graças Rodrigues Paulino & UFMG & 4 & 1,70 \\
\hline Marilda do Couto Cavalcanti & Unicamp & 4 & 1,70 \\
\hline Roxane Helena Rodrigues Rojo & Unicamp & 4 & 1,70 \\
\hline Denise Bertóli Braga & Unicamp & 3 & 1,27 \\
\hline Hilário I. Bohn & UCPel & 3 & 1,27 \\
\hline Maria Lúcia Castanheira & UFMG & 3 & 1,27 \\
\hline Vilson José Leffa & UCPel & 3 & 1,27 \\
\hline Ana Lúcia Guedes Pinto & Unicamp & 2 & 0,84 \\
\hline Anna Maria Grammatico Carmagnani & USP & 2 & 0,84 \\
\hline Cileda de Queiroz e Silva Coutinho & PUC-SP & 2 & 0,84 \\
\hline Dione Lucchesi de Carvalho & Unicamp & 2 & 0,84 \\
\hline Inês Signorini & Unicamp & 2 & 0,84 \\
\hline Iole Maria Faviero Trindade & UFRGS & 2 & 0,84 \\
\hline Isabel Cristina Alves da Silva Frade & UFMG & 2 & 0,84 \\
\hline José Armando Valente & Unicamp & 2 & 0,84 \\
\hline Josênia Antunes Vieira & UnB & 2 & 0,84 \\
\hline Júlio Araújo & UFC & 2 & 0,84 \\
\hline Kelley Cristine Gonçalves Dias Gasque & UnB & 2 & 0,84 \\
\hline Leda Verdiani Tfouni & USP & 2 & 0,84 \\
\hline Loredana Limoli & UEL & 2 & 0,84 \\
\hline Manoel Luiz Gonçalves Corrêa & USP & 2 & 0,84 \\
\hline Maria Elias Soares & UFC & 2 & 0,84 \\
\hline Maria Estela Costa Holanda Campelo & UFRN & 2 & 0,84 \\
\hline Maria Teresa Tedesco Vilardo Abreu & UERJ & 2 & 0,84 \\
\hline Mary Elizabeth Cerutti-Rizzatti & UFSC & 2 & 0,84 \\
\hline Nilcéa Lemos Pelandré & UFSC & 2 & 0,84 \\
\hline Simone Zanon Moschen & UFRGS & 2 & 0,84 \\
\hline Sylvia Bueno Terzi & Unicamp & 2 & 0,84 \\
\hline Orientadores com 1 trabalho & -- & 115 & 48,52 \\
\hline Total & -- & 237 & 100,00 \\
\hline
\end{tabular}

Fonte: Elaboração da autora com dados da pesquisa. Os autores em negrito compõem a frente de orientadores. 
Percebeu-se uma ampla distribuição de orientadores, sendo que 115 orientaram apenas 1 trabalho ( $48,52 \%$ das teses) e 21 orientaram 2 trabalhos ( $8,86 \%$ das teses).

É importante identificar qual o grupo de orientadores é mais profícuo, ou seja, quais pessoas são responsáveis pelo maior número de orientação das teses. Assim, foi calculada a frente de pesquisa de orientadores, utilizando-se a Lei de Lotka para o cálculo da produtividade, em que o número de autores que totaliza n contribuições é aproximadamente igual a 1/n2. A Tabela 6 apresenta a produtividade dos 150 orientadores das teses.

\section{TABELA 6}

PRODUTIVIDADE DOS ORIENTADORES DAS TESES SOBRE LETRAMENTO

\begin{tabular}{cccc}
\hline ORIENTAÇÕES & $\begin{array}{c}\text { FREQUÊNCIA ABSOLUTA } \\
\text { DE ORIENTADORES }\end{array}$ & $\begin{array}{c}\text { FREQUÊNCIA ACUMULADA } \\
\text { INVERSA DE AUTORES* }\end{array}$ & $\begin{array}{c}\text { FREQUÊNCIA RELATIVA } \\
\text { (\%) }\end{array}$ \\
\hline 1 & 115 & 150 & 76,67 \\
2 & 21 & 35 & 14,00 \\
3 & 4 & 14 & 2,67 \\
\hline 4 & 4 & 10 & $\mathbf{2 , 6 7}$ \\
\hline 5 & 1 & 6 & 0,67 \\
6 & 1 & 5 & 0,67 \\
8 & 2 & 4 & 1,33 \\
12 & 1 & 2 & 0,67 \\
\hline 13 & 1 & 1 & 0,67 \\
\hline
\end{tabular}

* Os valores da terceira coluna foram obtidos subtraindo a frequência absoluta da frequência acumulada inversa, iniciando pelo valor total de autores $(n=150)$.

Fonte: Elaboração da autora com dados da pesquisa.

Na Tabela 6, subtraindo-se o valor da frequência absoluta da primeira linha (que equivale aos orientadores com 1 orientação) da frequência acumulada inversa da primeira linha (que equivale ao total de orientadores), obtém-se o valor da frequência acumulada inversa da segunda linha; subtraindo-se o valor da frequência absoluta da segunda linha da frequência acumulada inversa da segunda linha, obtém-se o valor da frequência acumulada inversa da terceira linha, e assim sucessivamente, até obter todos os valores da terceira coluna.

Para calcular a frente de pesquisa, deve-se encontrar a raiz quadrada do valor total do número de autores $(\sqrt{150})$, o que resulta em 12,25 . Como não se obteve um número inteiro, foi necessário arredondá-lo. Porém, segundo Maroldi (2017), não há orientação sobre arredondar esse valor para baixo ou para cima. Sendo assim, deve-se adotar um dos seguintes conceitos: frente de pesquisa ampla (FPA) ou frente de pesquisa restrita (FPR):

1) frente de pesquisa ampla (FPA) - adota-se nos casos em que a diferença $(\Delta)$ entre os valores inteiros do cálculo da $(\sqrt{ } n)$ de Price for menor que $2 \%$ do total dos autores com uma única contribuição (y1);

2) frente de pesquisa restrita (FPR) - adota-se nos casos em que a diferença $(\Delta)$ entre os valores inteiros do cálculo da $(\sqrt{ } n)$ de Price for maior ou igual a $2 \%$ do total dos autores com uma única contribuição ( $\left.y_{1}\right)$. (MAROLDI, 2017, p. 138)

Não há como localizar o valor 12,25 na terceira coluna da Tabela 6, sendo preciso encontrar os valores aproximados, ou seja:

- 10 , que corresponde a 4 orientadores, que orientaram 4 trabalhos;

- 14 , que corresponde a 4 orientadores, que orientaram 3 trabalhos. 
Assim, a frente de pesquisa está entre 10 e 14 orientadores, localizada no destaque da Tabela 6. Ao calcular a diferença entre as frequências acumuladas inversas dos dois grupos de autores, obtém-se o valor 4, ou seja: $\Delta=14-10=4$. Nesse caso, para computar a frente de pesquisa, deve-se realizar o seguinte cálculo:

$(\Delta / \mathrm{y} 1)^{*} 100=(4 / 115)^{*} 100=3,48 \%$.

Como 3,48\% > 2\% do total dos orientadores com 1 única orientação, adotou-se a frente de pesquisa restrita, ou seja, o conjunto com menor número de orientadores, o qual corresponde aos 10 orientadores com 4 ou mais orientações, apresentados de forma decrescente de frequência de citações, os quais aparecem marcados em negrito na Tabela 6.

Encontrando-se esse parâmetro, foi possível localizar a frente de pesquisa dos orientadores das teses sobre letramento. A Tabela 6 apresenta os 10 orientadores mais profícuos marcados em negrito: 4 professores da Unicamp, 2 da UnB, 1 da USP, 1 da UFRN, 1 da UFRGS e 1 da Universidade Federal de Minais Gerais (UFMG). Dentre essas 6 IES, 5 aparecem no topo do ranque de instituição de defesa de teses (Tabela 2), respectivamente: Unicamp, USP, UnB, UFRGS e UFMG.

A Pontifícia Universidade Católica de São Paulo (PUC-SP), apesar de estar na sexta posição no ranque de instituição de defesa de teses (Tabela 2), não aparece no ranqueamento da frente de orientadores, pois, nessa IES, as 13 teses foram orientadas por 12 orientadores. A UFC também aparece em sexta posição no ranque de instituição (Tabela 2), mas não consta na frente de pesquisa de orientadores, pois as 13 teses defendidas nessa IES foram orientadas por 9 pessoas.

Em relação ao gênero dos autores e orientadores das teses, utilizou-se o critério onomástico, ou seja, o gênero foi contabilizado conforme o nome registrado no próprio trabalho, confirmado pela presença de expressões como prof., profa., dr. ou dra. nas folhas de aprovação, fichas catalográficas ou indicações nos agradecimentos (amigo, orientadora, etc.), caso presentes. Quando da impossibilidade de confirmação por indicações nas próprias teses, foram consultados os currículos Lattes ou páginas das instituições de trabalho dos autores, para verificar a presença de termos como "graduada", "professor", “coordenadora”, etc. Entretanto, não foram confirmadas possíveis alterações posteriores na identidade de gênero e/ou no nome social. Ressalta-se que foram usados os termos "homem" e "mulher" para se referir, binária e respectivamente, ao gênero masculino e ao gênero feminino, tendo em vista a impossibilidade de confirmar as identidades de gênero possíveis.

Percebeu-se a predominância de autoras e orientadoras do gênero feminino na pesquisa sobre letramento. Dentre os 150 orientadores, $74 \%(n=111)$ são do gênero feminino e $26 \%(n=39)$ do gênero masculino. Dos 237 autores das teses, 82,28\% são do gênero feminino ( $\mathrm{n}=195$ ) e 17,72\% do gênero masculino $(\mathrm{n}=42)$.

Em relação aos orientadores que têm bolsa produtividade em curso, 78,79\% ( $n=26$ ) são do gênero feminino e $21,21 \%(n=7)$ são do gênero masculino. Quanto à frente de pesquisa dos orientadores, $100 \%$ é formada pelo gênero feminino.

A presença de autores e orientadores do gênero masculino da frente de pesquisa que são contemplados com bolsa produtividade é muito inferior e só ultrapassa 1/4 na autoria das teses.

A presença feminina não pode ser avaliada sem se considerar questões de acesso e promoção na carreira, remuneração salarial e a subdivisão da ciência em áreas. Para Olinto (2011), a supremacia do gênero feminino na academia é falsa, pois barreiras sutis e enraizadas implicam dificuldades de alcançar postos mais altos e fomento à pesquisa.

Segundo dados do Conselho Nacional de Desenvolvimento Científico e Tecnológico (CNPq, 2018), de 2001 a 2015 foram concedidas 49,53\% de bolsas para mulheres e 50,47\% para homens, o que revela uma distribuição bem equilibrada. Em relação a bolsas no exterior no mesmo período, esse equilíbrio é um pouco abalado, com $43,67 \%$ para mulheres e $56,33 \%$ para homens. Entretanto, essa pretensa equidade aparece somente quando somados os dados gerais, mas, quando avaliada a distribuição de homens e mulheres nas grandes áreas do conhecimento, as disparidades são 
percebidas. A maioria das bolsas foram concedidas a mulheres na Saúde (67,06\%), Humanidades (60,80\%) e Biológicas (60,54\%). Já os homens tiveram a maior parte das bolsas na Engenharia e Computação (66,05\%) e nas Ciências Exatas e da Terra (65,90\%).

Para Lima, Braga e Tavares (2015), apesar de a participação feminina na ciência ter aumentado, existe uma exclusão horizontal, com pequena presença feminina em determinadas áreas, e a exclusão vertical, com poucas mulheres nos postos mais prestigiados.

\section{CONSIDERAÇÕES FINAIS}

Com o objetivo de compreender como se dá a constituição do campo científico sobre letramento no Brasil, foram levantados indicadores bibliométricos com base em um corpus de 237 teses depositadas na BDTD.

Percebeu-se que houve crescimento de pesquisas de doutorado sobre letramento na BDTD entre 1997 e 2016, sendo que a maior parte das 237 teses analisadas, ou 88,6\%, foi defendida entre 2007 e 2016. Uma queda foi notada em 2016, a qual ainda não pode ser considerada como diminuição de interesse pelo tema, o que pode ser confirmado por futuras pesquisas.

Os dados permitiram revelar um desequilíbrio no desenvolvimento de pesquisas sobre letramento no país, com grande concentração da produção em poucas regiões, instituições e pessoas. O Sudeste concentra a maior parte de teses sobre a temática (51,48\%), seguido das regiões Sul $(22,78 \%)$, Centro-Oeste $(13,08 \%)$ e Nordeste $(12,66 \%)$, sendo que nenhum trabalho do corpus analisado foi desenvolvido no Norte. Os dados chamam a atenção para a hegemonia do Sudeste na produção de pesquisas sobre a temática de um lado e a ausência de trabalhos na região Norte do outro, ressaltando as desigualdades socioeconômicas do país, que resvalam na pós-graduação e na pesquisa acadêmica. Outro indicador da desigualdade na produção sobre letramento é o fato de que 13 estados não apresentaram pesquisa de doutorado sobre o tema.

As teses sobre letramento foram realizadas em 27 IES, sendo as mais produtivas: Unicamp (18,99\%), USP (12,66\%), UnB (12,66\%) e UFRGS (9,28\%), sendo que 53,59\% da produção sobre letramento estão concentradas nas 4 primeiras IES.

O cálculo da frente de orientadores mais profícuos permitiu verificar a existência de um grupo de 10 docentes com maior número de orientações, respectivamente: Stella Maris Bortoni-Ricardo (5,49\%), Angela Kleiman (5,06\%), Maria Izabel Santos Magalhães (3,38\%), Walkyria Maria Monte Mór (3,38\%), Maria do Socorro Oliveira (2,53\%), Raquel Salek Fiad (2,12\%), Luciene Juliano Simões (1,7\%), Maria das Graças Rodrigues Paulino (1,7\%), Marilda do Couto Cavalcanti $(1,7 \%)$ e Roxane Helena Rodrigues Rojo (1,70\%).

Em relação ao gênero, constatou-se a maior presença feminina no campo do letramento: $74 \%$ das orientações, $82,28 \%$ da autoria e $100 \%$ da frente de orientadores são mulheres, o que indica assimetrias de gênero.

Os indicadores bibliométricos aqui levantados ajudam na compreensão da constituição do campo científico sobre letramento no Brasil pela identificação de algumas de suas raízes históricas, podendo servir de ponto de apoio para futuras investigações e problematizações.

\section{REFERÊNCIAS}

ALMEIDA, Luciana da Silva. Livro didático de alfabetização e letramento: uma análise bibliométrica das produções acadêmicas. 2018. 89 f. Dissertação (Mestrado em Cognição e Linguagem) - Universidade Estadual do Norte Fluminense Darcy Ribeiro, Campos dos Goitacazes, 2018. Disponível em: http://bdtd.ibict.br/vufind/Record/UERJ_ a3ec16b69d0b0451203b0196908572ac. Acesso em: 18 dez. 2018. 
BOURDIEU, Pierre. Os usos sociais da ciência. São Paulo: Editora Unesp, 2004.

BRASIL. Ministério da Educação. Coordenação de Aperfeiçoamento de Pessoal de Nível Superior. Plano Nacional de Pós-Graduação: PNPG 2011-2020. Brasília: Capes, 2010. Disponível em: https://www.capes.gov.br/images/stories/download/ PNPG_Miolo_V2.pdf. Acesso em: 8 nov. 2018.

CADAMURO, Liz. História da educação no Brasil: um estudo bibliométrico de teses e dissertações. 2011. 118 f. Dissertação (Mestrado em Educação) - Universidade Federal de São Carlos, São Carlos, 2011.

CERUTTI-RIZZATTI, Mary Elizabeth. Letramento: uma discussão sobre implicações de fronteiras conceituais. Educação e Sociedade, Campinas, SP, v. 33, n. 118, p. 291-305, jan./mar. 2012. Disponível em: http://www.scielo.br/pdf/es/v33n118/ v33n118a18.pdf. Acesso em: 24 jul. 2014.

CIRANI, Claudia Brito Silva; CAMPANARIO, Milton de Abreu; SILVA, Heloisa Helena Marques da. A evolução do ensino da pós-graduação senso estrito no Brasil: análise exploratória e proposições para pesquisa. Avaliação: Revista da Avaliação da Educação Superior, Campinas, SP, v. 20, n. 1, p. 163-187, mar. 2015. Disponível em: http://www.scielo.br/pdf/aval/ v20n1/1414-4077-aval-20-01-00163.pdf. Acesso em: 21 jul. 2017.

CONSELHO NACIONAL DE DESENVOLVIMENTO CIENTÍFICO E TECNOLÓGICO - CNPq. Tabela 2.9.3: número de bolsas-ano por grande área segundo o sexo do bolsista. 2018. Disponível em: http://memoria.cnpq.br/documents/10157/4000bfacaca3-470e-b182-dc29e0073987. Acesso em: 9 nov. 2018.

FERREIRA, Alessandro; BARREIRA, Gabriel. Alerj aprova prorrogação do estado de calamidade no RJ. G1, Rio de Janeiro, 23/05/2017, 16h16min. Disponível em: https://g1.globo.com/rio-de-janeiro/noticia/alerj-aprova-prorrogacao-do-estado-decalamidade-no-rj.ghtml. Acesso em: 6 nov. 2018.

GEE, James Paul. Social linguistics and literacies: ideology in discurses. 3th ed. Abingdon; New York: Routledge, 2008.

GEOCAPES: Sistema de Informações Georreferenciadas da Capes. Atualizado em 23 mar. 2018. Disponível em: https:/|geocapes.capes.gov.br/geocapes/. Acesso em: 24 out. 2018.

GERALDI, João Wanderley. A produção dos diferentes letramentos. Bakhtiniana: Revista de Estudos de Discurso, São Paulo, v. 9, n. 2, p. 25-34, dez. 2014. Disponível em: http://www.scielo.br/scielo.php?script=sci_arttext\&pid=S2176$45732014000200003 \& l n g=e n \& n r m=i s o$. Acesso em: $12 \mathrm{dez} .2018$.

GIL, Antonio Carlos. Como elaborar projetos de pesquisa. 4. ed. São Paulo: Atlas, 2002.

GONÇALVES, Bruna Angélica. Estado da arte de pesquisas sobre letramento no Brasil: como são pesquisadas agências, eventos e práticas além da escola? 2018. 135 f. Dissertação (Mestrado em Letras e Linguística) - Universidade Federal de Goiás, Goiânia, 2018.

GUIMARÃES, Isac Pimentel; BULHÕES, Rodrigo de Souza; HAYASHI, Maria Cristina Piumbato Innocentini; HAYASHI, Carlos Roberto Massao. Avaliação da pós-graduação no Brasil: como superar a imprecisão que reina entre nós. Quaestio: Revista de Estudos de Educação, Sorocaba, SP, v. 17, n. 1, p. 87-119, 2015. Disponível em: http://periodicos.uniso.br/ojs/ index.php/quaestio/article/view/2233/1926. Acesso em: 11 jun. 2020.

HAYASHI, Carlos Roberto Massao. 0 campo da história da educação no Brasil: um estudo baseado nos grupos de pesquisa. 249 f. 2007. Tese (Doutorado em Educação) - Universidade de São Carlos, São Carlos, 2007.

ITAQUI, Evelyse Ramos; TRINDADE, Iole Maria Faviero. O Estado do conhecimento dos estudos sobre alfabetização e alfabetismo/letramento no Rio Grande do Sul (1961-2006). In: SALÃO DE INICIAÇÃO CIENTífICA, 19., 2007, Porto Alegre. Anais eletrônicos [...] Porto Alegre: UFRGS, 2007. Disponível em: https://lume.ufrgs.br/handle/10183/58214. Acesso em: 6 fev. 2018.

JAPIASSU, Hilton. Interdisciplinaridade e patologia do saber. Rio de Janeiro: Imago, 1976. (Logoteca).

LIEVORE, Caroline; PICININ, Claudia Tania; PILATTI, Luiz Alberto. As áreas do conhecimento na pós-graduação stricto sensu brasileira: crescimento longitudinal entre 1995 e 2014. Ensaio: Avaliação e Políticas Públicas em Educação, Rio de Janeiro, v. 25, n. 94, p. 207-237, jan./mar. 2017. Disponível em: http://www.scielo.br/scielo.php?pid=S010440362017000100207\&script=sci_abstract\&tlng=pt. Acesso em: 24 out. 2018.

LIMA, Betina Stefanello; BRAGA, Maria Lúcia de Santana; TAVARES, Isabel. Participação das mulheres nas ciências e tecnologias: entre espaços ocupados e lacunas. Revista Gênero, Niterói, RJ, v. 16, n. 1, 2015. Disponível em: www. revistagenero.uff.br/index.php/revistagenero/article/view/743. Acesso em: 9 nov. 2018.

MACIEL, Francisca Izabel Pereira. Alfabetização no Brasil: pesquisas, dados e análise. In: MORTATTI, Maria do Rosário Longo; FRADE, Isabel Cristina Alves da Silva (org.). Alfabetização e seus sentidos: o que sabemos, fazemos e queremos? Marília: Oficina Universitária; São Paulo: Editora Unesp, 2014. p. 109-129. 
MAROLDI, Alexandre Masson. Estudos bibliométricos sobre educação indígena: frente de pesquisa, vida média e obsolescência da literatura citada em teses e dissertações. 2017. 205 f. Tese (Doutorado em Educação) - Universidade Federal de São Carlos, São Carlos, 2017.

MONTEIRO, Maria Iolanda. Alfabetização e letramento na fase inicial da escolarização. São Carlos: EDUFScar, 2010.

MORTATTI, Maria do Rosário Longo. Os sentidos da alfabetização: São Paulo/1876-1994. São Paulo: Editora Unesp, 1999.

MORTATTI, Maria do Rosário Longo. Produção acadêmica brasileira sobre alfabetização: avaliação da qualidade e impacto científico e social. In: MORTATTI, Maria do Rosário Longo; FRADE, Isabel Cristina Alves da Silva (org.). Alfabetização e seus sentidos: o que sabemos, fazemos e queremos? Marília: Oficina Universitária; São Paulo: Editora Unesp, 2014. p. 131-158.

MORTATTI, Maria do Rosário Longo; OLIVEIRA, Fernando Rodrigues de; PASQUIM, Franciele Ruiz. 50 anos de produção acadêmica brasileira sobre alfabetização: avanços, contradições e desafios. Interfaces da Educação, Paranaíba, MS, v. 5, n. 13, p. 6-31, 2014. Disponível em: https://periodicosonline.uems.br/index.php/interfaces/article/view/482. Acesso em: 11 jun. 2020.

NOBRE, Lorena Neves; FREITAS, Rodrigo Randow de. A evolução da pós-graduação no Brasil: histórico, políticas e avaliação. Brazilian Journal of Production Engineering, São Mateus, SP, v. 3, n. 2, p. 18-30, 2017. Disponível em: http://periodicos.ufes.br/BJPE/article/view/v3n2_3. Acesso em: 24 out. 2018.

OLINTO, Gilda. A inclusão das mulheres nas carreiras de ciência e tecnologia no Brasil. Inclusão Social, Brasília, v. 5, n. 1, p. 68-77, jul./dez. 2011. Disponível em: http://revista.ibict.br/inclusao/article/view/1667/1873. Acesso em: 25 jul. 2017.

OLIVEIRA, Rafaela Luiza Klitzke de. A alfabetização e o letramento: olhares da produção acadêmica nacional. 44 f. 2015. Trabalho de Conclusão de Curso (Licenciatura em Pedagogia) - Universidade Federal da Fronteira Sul, Chapecó, 2015. Disponível em: https://rd.uffs.edu.br/handle/prefix/1230. Acesso em: 15 fev. 2018.

PICCOLI, Luciana. Alfabetizações, alfabetismos e letramentos: trajetórias e conceitualizações. Educação e Realidade, Porto Alegre, v. 35, n. 3, p. 257-275, set./dez. 2010. Disponível em: seer.ufrgs.br/educacaoerealidade/article/ download/8961/10285. Acesso em: 6 mar. 2018.

PIETRUCHA, Jacek. Country-specific determinants of world university rankings. Scientometrics, v. 114, n. 3, p. 1129-1139, mar. 2018. Disponível em: https://link.springer.com/article/10.1007/s11192-017-2634-1. Acesso em: 3 nov. 2018.

RAMOS, Denise Marina. Educação de surdos: estudo bibliométrico de teses e dissertações (2010-2014). 2017. 214 f. Tese (Doutorado em Educação Especial) - Universidade Federal de São Carlos, São Carlos, 2017.

SANFELICE, José Luís. A política educacional do estado de São Paulo: apontamentos. Nuances: Estudos sobre Educação, Presidente Prudente, SP, v. 17, n. 18, p. 146-159, jan./dez. 2010. Disponível em: http://revista.fct.unesp.br/index.php/ Nuances/article/viewFile/730/742. Acesso em: 5 fev. 2016.

SERRANO, Ana Cristina Rodrigues. O estado do conhecimento sobre a aquisição da escrita no Brasil. 2010. 112 f. Dissertação (Mestrado em Linguística Aplicada) - Universidade Estadual de Campinas, Campinas, 2010. Disponível em: http://bdtd. ibict.br/vufind/Record/CAMP_85446216b93ab4348efaa45871a99f2f. Acesso em: 13 dez. 2018.

SILVA, Márcia Regina da; HAYASHI, Carlos Roberto Massao; HAYASHI, Maria Cristina Piumbato Innocentini. Análise bibliométrica e cientométrica: desafios para especialistas que atuam no campo. InCID: Revista de Ciência da Informação e Documentação, Ribeirão Preto, SP, v. 2, n. 1, p. 110-129, jan./jun. 2011. Disponível em: http://www.revistas.usp.br/incid/ article/view/42337. Acesso em: 16 jun. 2017.

SILVA, Rosemary Cristina da. Produção científica em Sociologia da Educação: estudo bibliométrico do Banco de Teses da Capes. 2013. 173 f. Tese (Doutorado em Educação) - Universidade Federal de São Carlos, São Carlos, 2013.

SOARES, Magda. Letramento: um tema em três gêneros. Belo Horizonte: Autêntica, 2016.

SPERRHAKE, Renata; TRINDADE, Iole Maria Faviero. Alfabetização e alfabetismo/letramento: mapeando teses e dissertações produzidas no Rio Grande do Sul entre 1975 e 2006. In: SALÃO DE INICIAÇÃO CIENTÍFICA PUCRS, 10., 2009, Porto Alegre. Anais eletrônicos [...] Porto Alegre: PUCRS, 2009. Disponível em: http://www.pucrs.br/edipucrs/XSalaoIC/ Ciencias_Humanas/Educacao/70591-RENATASPERRHAKE.pdf. Acesso em: 28 nov. 2018.

STREET, Brian V. What's "new” in New Literacy Studies? Critical approaches to literacy in theory and practice. Current Issues in Comparative Education, v. 5, n. 2, p. 77-91, May 2003. 
TFOUNI, Leda Verdiani. Letramento e alfabetização. São Paulo: Cortez, 1995.

TRINDADE, Iole Maria Faviero; ITAQUI, Evelyse Ramos; COSTA, Luiza da Sillva. As pesquisas de alfabetização e alfabetismo/letramento em foco. In: CONGRESSO DE LEITURA, 16., 2007, Campinas. Anais eletrônicos [...] Campinas: ALB, 2007. v. 1. p. 1-10. Disponível em: https://lume.ufrgs.br/bitstream/handle/10183/30274/000646285.pdf?sequence=1. Acesso em: 9 nov. 2018.

\section{COMO CITAR ESTE ARTIGO}

SOUSA, Raquel Juliana Prado Leite de. Produção científica sobre letramento: mapeamento bibliométrico das teses da BDTD (1997-2016). Cadernos de Pesquisa, São Paulo, v. 50, n. 176, p. 494-514, abr./jun. 2020. https://doi.org/10.1590/198053146655 